\title{
Geldanamycin and its derivatives as Hsp90 inhibitors
}

Magdalena Gorska ${ }^{1}$, Urszula Popowska ${ }^{1,3}$, Alicja Sielicka-Dudzin ${ }^{2}$, Alicja Kuban-Jankowska ${ }^{1}$, Wojciech Sawczuk ${ }^{1}$, Narcyz Knap ${ }^{1}$, Giuseppe Cicero ${ }^{5}$, Fabio Bucchieri ${ }^{4}$, Michal Wozniak ${ }^{1,3}$

${ }^{I}$ Department of Medical Chemistry, Medical University of Gdansk, Gdansk, Poland, ${ }^{2}$ Department of Bioenergetics and Physiology of Exercise, Medical University of Gdansk, Gdansk, Poland, ${ }^{3}$ College of Health, Beauty Care and Education in Poznan, Faculty in Gdynia, Gdynia, Poland, ${ }^{4}$ Department of Experimental Biomedicine and Clinical Neurosciences, Section of Human Anatomy "Emerico Luna", University of Palermo, Palermo, Italy, "Department of Oncology, Medical Oncology Unit, University of Palermo, Palermo, Italy

\section{TABLE OF CONTENTS}

\section{Abstract}

2. Introduction

3. Hsp90 inhibitors

3.1. Geldanamycin and its derivatives

3.2. Influence of geldanamycin on the major Hsp90 client proteins - possible anti-cancer targets

\subsubsection{Src Family kinases}

3.2.2. Rafl kinase

3.2.3. Cyclin-dependent kinases Cdk4, Cdk6

3.2.4. Transforming growth factor TGF-beta

3.2.5. Mutated p53

3.3 Other Hsp 90 inhibitors

3.3.1. Radicicol

3.3.2. Novobiocin

3.3.3. STA-9090 and STA-1474

4. Summary and perspective

5. Acknowledgments

6. References

\section{ABSTRACT}

The Hsp90 molecule, one of the most abundant heat shock proteins in mammalian cells, maintains homeostasis and prevents stress-induced cellular damage. Hsp90 is expressed under normal conditions at a level of about $1-2 \%$ of total proteins, while its expression increases 2-10 fold in cancer cells. The two main constitutively expressed isoforms of Hsp90 are known as Hsp90-alpha and Hsp90-beta, and their upregulation is associated with tumor progression, invasion and formation of metastases, as well as development of drug resistance. The Hsp90 is a key target for many newly established, potent anticancer agents containing Hsp90 N-terminal ATP binding inhibitors, such as geldanamycin, and its analogues 17AAG and 17DMAG. The therapeutic usage of geldanamycin has been limited due to its poor water solubility and severe hepatotoxicity. Therefore, its analogues, including 17AAG, 17DMAG, Tanespimycin and Retaspimycin hydrochloride, with improved pharmacokinetic profiles, have been developed.

\section{INTRODUCTION}

Heat shock proteins (Hsps) belong to chaperones that are responsible for maintaining homeostasis of the organisms and promoting cell survival induced by increased temperature as well as various chemical and physical factors. One of the most abundant eukaryotic HSPs is Hsp90, ubiquitously expressed protein of a molecular weight of $90 \mathrm{kDa}$, whose expression level is estimated at $1-2 \%$ of total proteins under normal conditions $(1,2)$.

In humans, there have been identified two cytoplasmic isoforms of Hsp90 - Hsp90-alpha and Hsp90beta, the endoplasmic reticulum homolog Glucoseregulated Protein 94 (GRP94), mitochondrial matrix TRAP1 and Hsp90N while in mice Hsp84 and Hsp86 are found. Although both Hsp90-alpha and Hsp90-beta are constitutively expressed isoforms, the first one seems to be more inducible (3). Researches typically associate Hsp90alpha expression with tumor progression and sustained 


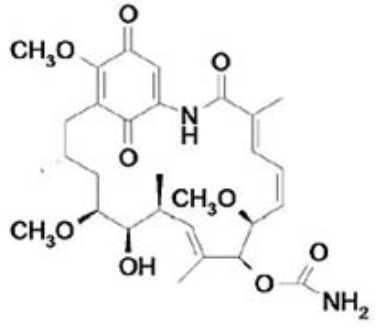

a

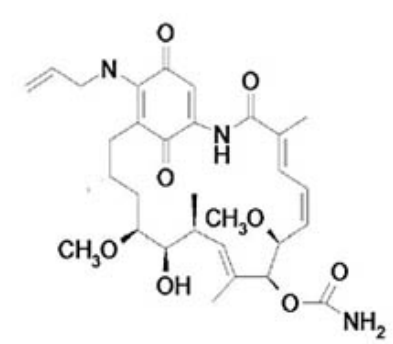

b

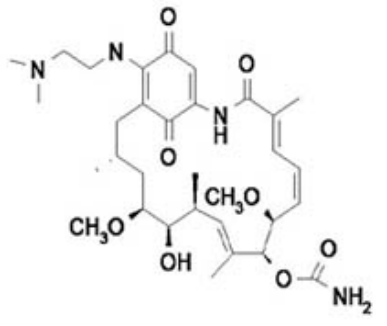

C
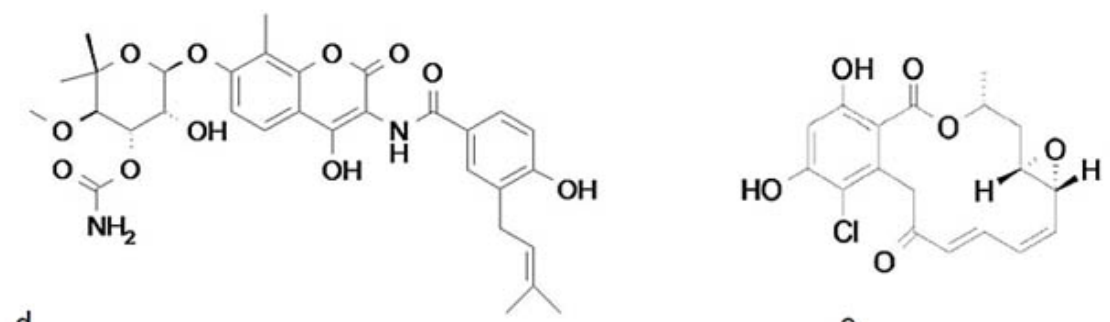

Figure 1. Chemical structures of Hsp90 inhibitors, $a$. Geldanamycin, $b$. 17AAG, $c$. 17-DMAG, $d$. Novobiocin, $e$. Radicicol.

proliferation of cancer cells (4-6) while the Hsp90-beta isoform seems to be responsible for development of drug resistance $(7,8)$. Hsp90 exists as dimer, whereas homodimers of Hsp90 are more common than heterodimers. In stressed or injured cells, the Hsp90 protein accumulates in the nucleus and is involved in guarding the so called cytosolic molecular chaperone complex $(9,10)$. The molecule maintains solubility, stability, intracellular location and function of Hsp90 client proteins involved, among others, in promoting cell proliferation and survival. Amongst the Hsp90 client proteins there can be distinguished factors such as a mutated form of p53 (11), tyrosine kinases Src kinase family (12), Weel kinase (13), serine/threonine kinases like Rafl (14), and enzymes including nitric oxide synthases involved in oxidative and nitrative stress (15, 16). Hanahan and Weinberg have characterized some typical capabilities shared by almost all cancer types. Fascinatingly, Hsp90 and its client proteins take part in maintaining six of these capabilities mentioned in the article by influencing the regulation of key factors and proteins:

1. Self-suffciency in growth signaling (Human Epidermal Growth Factor Receptor- HER2 also known as ErbB2)

2. Insensitivity to anti-growth signaling (Cyclin dependent kinases Cdc4, Cdc6, Cyclin D)

3. Capacity to avoid programmed cell death like apoptosis (AKT kinase)

4. Chronic aniogenesis (Hypoxia-induced factorlalpha HIF1-alpha, Vascular Endothelial Growth Factor VEGF)

5. Metastasis (metalloproteases MMP2, urokinase)

6. Infinite proliferative potential (telomerase) (17)
Interestingly, the Hsp90 protein is expressed at a level 2-10 fold higher in cancer cells compared to unstressed, healthy ones, suggesting that the protein is one of the major components involved in cancer cell survival and/or in tumor growth (18).

The mammalian isoforms of Hsp90 have a conserved structure containing: a C-terminal domain (11-15 $\mathrm{kDa}$ ), that provides constitutive dimerization of protein, a Hsp90 client protein binding domain (38-44 kDa), and an N-terminal ATP binding site $(24-28 \mathrm{kDa})$, responsible for impermanent dimerization. ATP binding is essential for forming a mature dimer of the Hsp90 capable to bind, chaperone and leave its client proteins. Primarily, a Hsp90 client protein is bound to a Hsp40/Hsp70 chaperone complex, that subsequently binds to the Hsp90 thanks to HOP (Hsp90/Hsp70 Organizing Protein). Finally, the Hsp90 binds ATP molecule thus resulting in a dissociation of the HOP and Hsp40/Hsp70 complex, and in an association of Hsp90 with its cochaperones and client protein. Co-chaperones e.g. Hsp70, Hsp40, p23 and CHIP accompany Hsp90 in nucleotide exchange, ATP hydrolysis, chaperoning and degradation of its client proteins. Non-chaperoned Hsp90 client proteins undergo proteasomal degradation by E3 ubiquitin ligases, such as CHIP (Carboxyterminus of Hsp70 Interacting Protein) (19-21).

\section{HSP90 INHIBITORS}

\subsection{Geldanamycin and its derivatives}

Geldanamycin (GA) and its derivatives (Figure 1) have been reported to possess multiple pharmacological properties- antitumoral properties, inhibition of angiogenesis and metastasis of diseases such as multiple myeloma (22), as well as breast (23) or prostate cancer (24). GA have been identified from Streptomyces hygrocopicus in 1970 as tyrosine kinase inhibitor $(25,26)$. Nowadays it is 


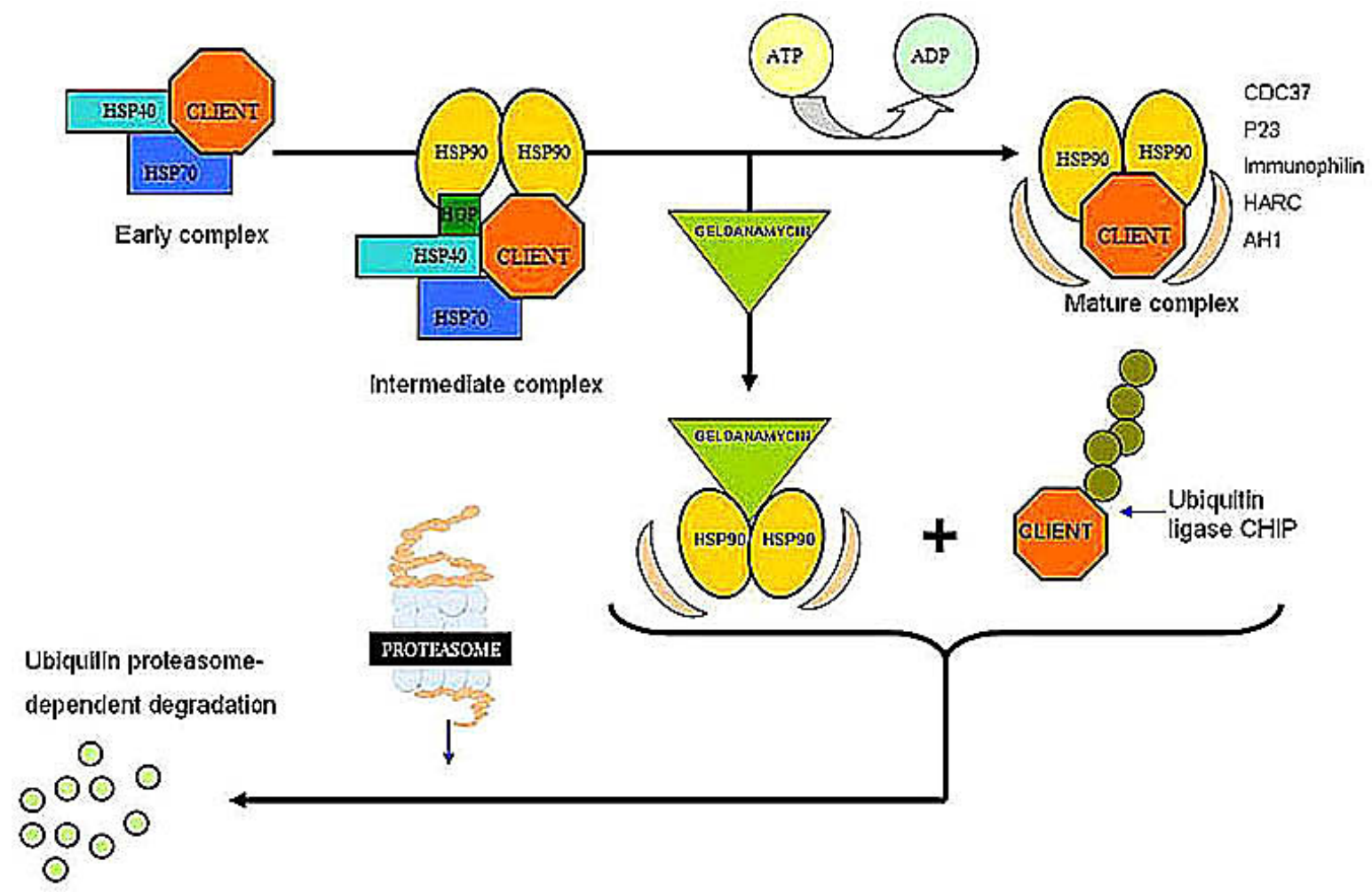

Figure 2. Geldanamycin as depletor of Hsp90. Primarily Hsp90 client protein binds to Hsp40/Hsp70 early chaperone complex, subsequently undergoes Hsp90 dimer- binding thanks to HOP- Hsp90/Hsp70 Organizing Protein forming intermediate complex. ATP molecule hydrolysis results in dissociation of HOP and Hsp40/Hsp70, and successively in association of Hsp90 with its cochaperones, client protein. Geldanamycin binds to N-terminal ATP-binding site of Hsp90, perturbs formation of mature complex and leads to proteasomal degradation by E3 ubiquitin ligase like CHIP (Carboxy-terminus of Hsp70 Interacting Protein) (based on 76).

known as potent small molecule inhibitor of Hsp90. GA binds to Hsp90 N-terminal ATP binding site, similarly to radicicol, another Hsp90 inhibitor (27). GA inhibits Hsp90 ATPase activity, affecting the dissociation of mature chaperone Hsp90 complex and the degradation of Hsp90 client proteins in proteasomes by E3 ligase (28) (Figure 2). The mechanisms involved in proteasomal degradation of Hsp90 client proteins and destabilization of Hsp90 complexes are relatively well understood, but little is known about effects of GA on the modulation of Hsp90 genes at the transcriptional level. Expression of Hsps is regulated by the heat-shock transcription factors (HSFs), that bind to HSE after activation and conduce to the transactivation of heat shock genes. In mammalian cells, three isoforms of HSFs can be distinguished: stressactivated HSF1, developmentally regulated HSF2, tissuespecifically regulated $\operatorname{HSF} 4(29,30)$. Interestingly, it has been revealed that HSF1 is a client protein of Hsp90 and that GA leads to transactivation of the heat-shock genes involving the Hsp90 gene. GA acts as an inhibitor of the Hsp90 function, but also as an inducer of heat-shock genes, including the Hsp90 gene. Moreover, GA can induce expression of many stress proteins, such as GRPs and Hsp90s, in a concentration-dependent and cell-specific manner $(31,32)$. Despite its influence on the Hsp90 function and expression of heat-shock genes and proteins, the distinct mechanism of action of GA is associated with the induction of oxidative stress and production of reactive oxygen species (ROS) related to its quinone group (33). For that reason GA provokes not only TNF-alpha-mediated or intrinsic apoptotic pathways, but also oxidative-stress induced apoptosis (34). Unfortunately, the stress response induced by treatment with this compound can also be cause resistance to therapy with GA, and seems to be associated not only with P-glycoprotein expression but, predominantly, with the stress-induced expression of Hsp70 and Hsp27 proteins. Andrea K. McCollum, Cynthia J. TenEyck and colleagues have stated that a knockdown of Hsp27 or Hsp70 is sufficient to reverse resistance to 17-AAG and EC78 (analogues of GA) in a A549 cell line (selected for GA resistance), while inhibition of P-glycoprotein by verapamile is ineffective (35).

Regardless of the pleiotropic activities of GA involving its potent anticancer properties, this compound cannot be evaluated in clinical trials because of its hepatotoxicity, poor water solubility and limited oral bioavailability. Thankfully, modified GA derivatives have been developed as potential drug candidates. 17AAG (17(Allylamino)-17-demethoxygeldanamycin, NSC 330507, KOS 953, Tanespimycin), a geldanamycin analogue has been evaluated in Phase II/III clinical trials, and has been 
found to possess a lower toxicity, a better stability than GA and to retain a potent anticancer activity even at nanomolar concentrations, although its binding to Hsp90 has resulted weak. It has been evaluated in phase II/ III clinical trials for treatment of multiple myeloma, metastatic melanoma and breast cancer. (36-39). There is evidence of its high activity toward cancers cells both in monotherapy and in combination of therapies with drugs such as bortezomib, sorafenib or trastuzumab (40-42). Due to the fact that tansepimycin is water insoluble, the most appropriate drug formulations for this compound are still being researched. In the "Phase II trial of the Hsp90 inhibitor tanespimycin $($ Tan) + trastuzumab (T) in patients (pts) with HER2positive metastatic breast cancer (MBC)" the patients were given cremophor-based 17AAG combined with antihistamine/steroid premeds and tanespimycin in form of a suspension without premeds. The toxicity after drug administration was found to be very controllable; the main side effects were fatigue $(39 \%)$, diarrhea $(33 \%)$, dizziness (24\%) and headache (19\%). Both used forms of 17AAG have been shown to have similar safety profiles, and trial outcomes have been encouraging as well: among others, a $75 \%$ decrease in liver metastases, a $57 \%$ decrease in lymph node, liver, and breast lesions were reported (43).

Subsequently a second-generation GA analogue has been developed: 17-dimethylaminoethylamino-17demethoxygeldanamycin (17-DMAG, Alvespimycin, KOS1022, Kosan), characterized by improved properties. Studies in vitro have revealed 17-DMAG is more specific for Hsp90 complexes in cancer cells compared with healthy cells. In addition, it is water-soluble, and it has been reported to have a better oral bioavailability or even a marginally superior activity comparing to 17AAG. Moreover, 17-DMAG has been conveyed to be widely distributed to tissues, and quantitatively much less metabolized than 17-AAG (44-46). Another GA analogue, IPI-504 (Retaspimycin hydrochloride, 18, 21-Didehydro17-demethoxy-18,21-dideoxo-18,21-dihydroxy-17- (2propenylamino)geldanamycin) is a novel potent watersoluble Hsp90 inhibitor. It has been reported that it IPI-504 is an active form of $17 \mathrm{AAG}$, as tanespimycin is metabolized to retaspimycin. IPI-504 is especially effective in the treatment of Non-Small Cell Lung Cancer (NSCLC), Gastrointestinal Stromal tumors (GIST) and Soft Tissue Sarcomas (STS) (47-49); moreover, it is also effective both as a single agent as well as acting synergistically with bortezomib and docetaxel (Taxotere) in solid tumors (41, $50)$.

Since Hsp90 acts as a dimer, Hong Zhang and colleagues compared the pharmacological properties of 17AAG and dimer ansamycins with prolonged inhibitory activity CF237 and CF483. The dimers were characterized by extremely high Hsp90 binding affinity, forming extraordinary stable complexes with the target protein, thus resulting in improved activity and in an increased efficacy and period of action of the dimers in comparison to monomer 17AAG. There are also disadvantages of dimer ansamycin use in therapy, firstly owing to their high reactivity with water: they are in fact poorly water-soluble, due to their high affinity to target proteins and irreversible inhibition (their action cannot be reversed by ceasing their administration); moreover, they can cause tolerability issues as a result of forming complexes also with non-target proteins (51).

3.2. Influence of geldanamycin on the major Hsp90
client proteins- possible anti-cancer targets
3.2.1. Src family kinases
P $60 \mathrm{v}-\mathrm{src}$ is the transforming protein of Rous sarcoma virus and client protein of Hsp90, complexed with the p50Cdc37 protein $(52,53)$. One of the major target proteins of p60v-src is Focal Adhesion Kinase (FAK), a nonreceptor protein-tyrosine kinase. P60v-src phosphorylates FAK, but, moreover, induces autophosphorylation and protects against the action of tyrosine phosphatases (54). High levels of both p60v-rsc and FAK protein conduce to a disregulation of the transmission of cell growth signaling and anchorindependent proliferation of the cells. Researches uncovered the presence of diminished levels of p60v-src and tyrosine phosphorylated proteins in mutant yeast with a lowered Hsp90 expression, with the consequent restoration of a normal cell cycle. GA and other ansamycin antibiotics were originally discovered as p60v-src inhibitors, while today it is known that this inhibition is indirect and affected by the destabilization of the Hsp90-p60v-src complex, leading to diminished levels of the tyrosine kinase $(55,56)$.

Conversely, the association between Hsp90 and cellular c-Src still seems to be unclear. Experiments have failed to detect Hsp90-c-Src complexes, in contrast to Hsp90-p60v-src, which are very stable and abundant (57). In yeast with a lowered Hsp90 level no differences were found in c-Src levels. Interestingly, GA leads to disruption of Hsp90-c-Src complexes and other Hsp90 complexes with Src kinases sharing homology in their C-termini with c-Src like Lck and Fgr kinases (58).

\subsubsection{Raf1 kinase}

Raf 1 protooncogene belongs to the serine/threonine kinases responsible for the regulation of cell proliferation, differentiation and apoptosis. It is a component of the MAPK (Mitogen-activated Protein Kinases)/ERK (Extracellular Signal-regulated Protein Kinases) signaling transduction pathway recruited by the activated Ras protein, a membrane-associated GTPase, after activation Rafl induces phophorylation of kinases such as ERK1, ERK2 or MAP kinase kinase MEK1 and MEK2 (59). Relatively to p60v-src, Raf1 forms complexes with Hsp90 and p50Cdc37. MEK1 kinase has likewise been found to associate with both Hsp90 and Raf1 $(60,61)$.

\subsubsection{Cyclin-dependent kinases Cdk4, Cdk6}

Cyclin-dependent kinases take part in the regulation of cell cycle in eukaryotic cells; one of the mechanisms of their action is phosphorylation/dephosphorylation. Cdc4 is the kinase responsible for triggering mitosis and the factor stimulating cells to transition from $\mathrm{G} 2$ to $\mathrm{M}$ phase by phosphorylation of the retinoblastoma protein. $\mathrm{Cdc} 4$ that is regulated partly by its association with cyclin $\mathrm{B}$, forms complexes with cyclinD, active in the nucleus. $\mathrm{Cdc} 4$ also forms complexes 
with Hsp90/p50Cdc37 in primed conformation, and after dissociation from the chaperone complex, it connects with cyclin D $(53,62)$. Through inhibition of the Hsp90 function, GA decreases the level of $\mathrm{Cdc} 4$ by post-translational destabilization similarly to Raf1 kinase. Cdk6, comparably to $\mathrm{Cdk} 4$, induces transition of cells through the G1 phase of cell cycle, being activated by interaction with cyclin $\mathrm{D}$ protein, and forms complexes with Hsp90/p50Cdc37 (53). It has been revealed that GA lowers the expression of Cdk4, Cdk6 and cyclin B, as well as inducing mostly G2 or M arrest in cancer cells like the glioblastoma U87MG cell line with the consequence of inhibiting cell cycle progression.

\subsubsection{Transforming growth factor TGF-beta}

TGF-beta, a member of the polypeptide growth factor family, is a cytokine involved in the regulation of cell proliferation, differentiation and survival. It is known well dichotomy of TGF-beta, which in normal epithelial cells acts as tumor suppressor and inducer of apoptosis, while in malignant cells, it works as a tumor promoter, stimulating proliferation, angiogenesis and metastases (63). There are different isoforms of TGF-beta, with a 70$80 \%$ homology in amino acids. One can distinguish two transmembrane protein receptors for TGF-beta with serine/threonine activity- TGF-beta type 1 receptor (TGFbetaRI) and TGF-beta type 2 receptor (TGF-beta RII); downstream effectors of TGF-beta are the Smads proteins that regulate the expression of target genes. GA has been reported to inhibit TGF-beta signaling through increased receptor ubiquitination, partly by increasing expression of inducible Hsp70, co-chaperone of Hsp90 expressed in the majority of cancer cells (64).

\subsubsection{Mutated p53}

Wild type p53 is a well known tumor suppressor protein that is involved in the adjustment of cell cycle progression, apoptosis. It is referred to as "the guardian of the genome", and characterized by very short half-life, with its mutated form being fairly stable; the latter interferes in the activity of wild type p53 by perturbing its activity and increasing drug resistance according to cells with mutations of p53 protein (65). Blagosklonny, Toretsky and Neckers (66) exposed the potential of GA to decrease mutated p53 level and half-life, in contrast to the wild type protein that is unaffected by drug therapy.

\subsection{Another Hsp90 inhibitors \\ 3.3.1. Radicicol}

Radicicol is a macrocyclic lactone antibiotic possessing epoxy $\alpha, \beta, \gamma$ - unsaturated carbonyl groups; it was isolated from the fungus Monosporium bonorden (67). Radiciol is a potent Hsp90 inhibitor that acts by interacting with its $\mathrm{N}$-terminal binding domain and triggering Hsp90 client proteins proteasomal degradation, similarly to GA and its analogues (27). Radicicol has been found to induce apoptosis even in 17AAG-resistant cancer cells. Possibly because of its unstable epoxy group, radicicol has failed to be effective in animal models, although it has been found to possess strong anti-cancer properties in vitro (68). Oxime derivatives of radicicol with enhanced stability, synthetized by Kyowa Hakko Kirin, are known as KF55823 and KF58333. Interestingly, despite of these two derivates achieving the same level of plasma concentrations, KF58333 showed significant antiproliferative and antitumor properties through depletion of Hsp90 in KPL-4 human breast cancer xenografts, unlike its stereoisomer KF58332; this finding suggests that oxime derivatives of radicicol may possess stereospecific antitumor properties (69).

\subsubsection{Novobiocin}

Novobiocin (Albamycin, Cathomycin) is an aminocoumarin antibiotic produced by Actinobacteria Streptomyces niveus (Streptomyces spheroids). In contrast with geldanamycin and radicicol, novobiocin binds to the C-terminal ATP binding site of Hsp90 (70); moreover, it also acts as an inhibitor of bacterial DNA gyrase (71). Similarly to ansamycin antibiotics, novobiocin affects the destabilization and degradation of Hsp90 client proteins involving Rafl, p60v-src, mutated p53 protein or AKT kinase $(72,73)$. An analogue of novobiocin, F-4, has been found to be more potent and efficient in comparison with its parental compound and even with the $\mathrm{N}$ terminal inhibitor 17AAG in prostate cancer cells (74).

\subsubsection{STA-9090 and STA-1474}

Novel Hsp90 inhibitors have been developed, that are not related to geldanamycin- derivatives of resorcinol, containing triazol ring in chain. STA-9090 and its pro-drug STA-1474 seem to be effective in vitro, at nanomolar concentrations, against multiple tumor cell lines including osteosarcoma. Both drugs bind to the ATP-binding domain at the N-terminus of Hsp90 and induce a degradation of Hsp90 client proteins (75).

\section{SUMMARY AND PERSPECTIVE}

Due to the fact that isoforms of HSP90 are implicated in cancer development, progression and formation of metastases, Hsp90 inhibitors are at the center of interest of oncologists and researches. One type of Hsp90 inhibitors are the benzoquinone ansamycin antibiotics, including herbimycin A, geldanamycin and its derivatives with enhanced pharmacokinetics and pharmacodynamics profile, while another one, dissimilar to benzoquinone antibiotics, is the Hsp90-binding small molecule-natural product, radicicol, and newly analogues of resorcinol with triazol ring in chain- STA-9090 and STA-1474. All of the aforementioned inhibitors possess a high affinity to binding to the N-terminal ATP binding site of Hsp90 and affect its function. Novobiocin is an antibiotic and a potent Hsp90 inhibitor that, in contrast to the abovementioned chemicals, interacts with the Cterminal ATP binding pocket. These anti-cancer agents or their derivatives have been developed in preclinical studies or already evaluated in clinical trials involving different kinds of malignancies such as multiple myeloma, breast or prostate cancer.

\section{ACKNOWLEDGEMENTS}

This article was founded by grant from Polish Ministry of Science and Higher Education N N401 634140 
and by grant from College of Health, Beauty Care and Education in Poznan.

\section{REFERENCES}

1. L. Neckers, T. W. Schulte, E. Mimnaugh: Geldanamycin as a Potential Anti-Cancer Agent: Its Molecular Target and Biochemical Activity. Invest New Drug 17 ,4, 361-373 (2003)

2. S. Takayama, J. C. Reed, S. Homma: Heat-shock proteins as regulators of apoptosis. Oncogene 22, 90419047 (2003)

3. P. Csermely, T. Schnaider, C. Soti, Z. Prohaszka, G. Nardai: The 90-kDa Molecular Chaperone Family: Structure, Function, and Clinical Applications. A Comprehensive Review. Pharmacol Therapeut 79, 2, 129 168 (1998)

4. Y. Yufu, J. Nishimura, H. Nawata: High constitutive expression of heat shock protein $90 \alpha$ in human acute leukemia cells. Leukemia Res 16, 6-7, 597-605 (1992)

5. V. Jerome, C. Vourc'h, E. E. Baulieu, M. G. Catelli: Cell cycle regulation of the chicken hsp90 alpha expression. Exp. Cell Res 205, 1, 44-51 (1993)

6. V. Jerome, J. Léger, J. Devin, E. E. Baulieu, M. G. Catell: Growth factors acting via tyrosine kinase receptors induce HSP90 alpha gene expression. GRF 4, 4, 317-27 (1991)

7. J. Bertram, K. Palfner, W. Hiddemann, M. Kneba: Increase of P-glycoprotein-mediated drug resistance by hsp 90 beta. Anticancer Drug 7, 8, 838-45 (1996)

8. X. Liu, L. Ye, J. Wang, D. Fan: Expression of heat shock protein 90 beta in human gastric cancer tissue and SGC7901/VCR of MDR-type gastric cancer cell line. CMJ $112,12,1133-7$ (1999)

9. L. H. Pearl, C. Prodromou: Structure, function, and mechanism of the Hsp90 molecular chaperone. Adv Protein Chem 59, 157-86 (2001)

10. W. B. Pratt, D. O. Toft: Regulation of signaling protein function and trafficking by the hsp90/hsp70-based chaperone machinery. Exp Biol Med 228, 2, 111-33 (2003)

11. M. V. Blagosklonny, J. Toretsky, L. Neckers: Geldanamycin selectively destabilizes and conformationally alters mutated p53. Oncogene 7, 11, 5, 933-9 (1995)

12. S. D. Hartson, R.L. Matts: Association of Hsp90 with Cellular Src-Family Kinases in a Cell-Free System Correlates with Altered Kinase Structure and Function. Biochemistry 33, 30, 8912-8920 (1994)

13. R. Aligue, H. Akhavan-Niak, P. Russell: A role for Hsp90 in cell cycle control: Weel tyrosine kinase activity requires interaction with Hsp90. EMBO J 15;,13, 24, 6099-6106 (1994)
14. T. W. Schulte, M.V. Blagosklonny, C. Ingui, L. Neckers: Disruption of the Raf-1-Hsp90 Molecular Complex Results in Destabilization of Raf-1 and Loss of Raf-1-Ras Association. J Biol Chem 270, 41, 24585-24588 (1995)

15. G. Antonova, H. Lichtenbeld, T. Xia, A. Chatterjee, C. Dimitropoulou, J. D. Catravas: Functional significance of hsp90 complexes with NOS and sGC in endothelial cells. Clin Hemorheol Micro 37, 1-2, 19-35 (2007)

16. T. Presley, K. Vedam, M. Velayutham, J. L. Zweier, G. Ilangovan: Activation of Hsp90-eNOS and increased NO generation attenuate respiration of hypoxia-treated endothelial cells. Am J Physiol - Cell Ph 295, 5, 1281-91 (2008)

17. D. Hanahan, R. A. Weinberg: The hallmarks of cancer. Cell 7, 100, 1, 57-70 (2000)

18. M. Ferrarini, S. Heltai, M. R. Zocchi, C. Rugarli: Unusual expression and localization of heat-shock proteins in human tumor cells. Int J Cancer 51, 4, 613-619 (1992)

19. J. P. Hendrick, F. Hartl: Molecular Chaperone Functions of Heat-Shock Proteins. Annu Rev Bioch 62, 349-384 (1993)

20. F. U. Hartl, M. Hayer-Hartl: Molecular Chaperones in the Cytosol: from Nascent Chain to Folded Protein. Science $295,5561,1852-1858$ (2002)

21. P. Connell, C. A. Ballinger, J. Jiang, Y. Wu, L. J. Thompson, J. Hohfeld, C. Patterson: The co-chaperone CHIP regulates protein triage decisions mediated by heatshock proteins. Nature Cell Biol 3, 1, 93-6 (2001)

22. P. G. Richardson, A. A. Chanan-Khan, M. Alsina, M. Albitar, D. Berman, M. Messina,C. S. Mitsiades, K. C. Anderson: Tanespimycin monotherapy in relapsed multiple myeloma: results of a phase 1 dose-escalation study. $B J$ Haematol 150, 4, 438-45 (2010)

23. J. L. Eiseman, J. Lan, T. F. Lagattuta, D. F. Hamburger, E. Joseph, J. M. Covey, M. J. Egorin: Pharmacokinetics and pharmacodynamics of 17demethoxy 17- ( ) (2dimethylamino)ethyl)amino)geldanamycin (17DMAG, NSC 707545) in C.B-17 SCID mice bearing MDA-MB231 human breast cancer xenografts. Cancer Chemoth Pharm 55, 1, 21-32 (2005)

24. Y. Suzuki, Y. Kondo, S. Hara, R. Kimata, T. Nishimura: Effect of the hsp90 inhibitor geldanamycin on androgen response of prostate cancer under hypoxic conditions. Int J Urol 17, 3, 281-5 (2010)

25. C. DeBoer, P .A. Meulman, R. J. Wnuk, D. H. Peterson: Geldanamycin, a new antibiotic. J Antibiot 23, 9, 442-7 (1970) 
26. L. Whitesell, S. D. Shifrin, G. Schwab, L. M. Neckers: Benzoquinonoid ansamycins possess selective tumoricidal activity unrelated to src kinase inhibition. Cancer Res 1, 52, 7, 1721-8 (1992)

27. M. K. Hadden, M. D. Lubbers, B. S. J. Blagg: Geldanamycin, Radicicol, and Chimeric Inhibitors of the Hsp90 Nterminal ATP Binding Site. Curr Topics in Med Chem 6,11, 1173-1182 (2006)

28. S. Murata, T. Chiba, K. Tanaka: CHIP: a qualitycontrol E3 ligase collaborating with molecular chaperones. Int J Biochem Cell B 35, 5, 572-578 (2002)

29. P. K. Sorger: Yeast heat shock factor contains separable transient and sustained response transcriptional activators. Cell 62, 793-805 (1990)

30. A. Nakai, M. Tanabe, Y. Kawazoe, J. Inazawa, R. I. Morimoto, K. Nagata: HSF4, a new member of the human heat shock factor family which lacks properties of a transcriptional activator. Mol Cell Biol 17, 1, 469-481 (1997)

31. M. T. Lai, K. L. Huang, W. M. Chang, Y. K. Lai: Geldanamycin induction of grp78 requires activation of reactive oxygen species via ER stress responsive elements in 9L rat brain tumor cells. Cell Signal 15, 6, 585-95 (2003)

32. C. C. Chao, F. C. Sun, C. H. Wang, C. W. Lo, Y. S. Chang, K. C. Chang, M. D. Chang, Y. K. Lai: Concerted actions of multiple transcription elements confer differential transactivation of HSP90 isoforms in geldanamycin-treated 9L rat gliosarcoma cells. J Cell Biochem 1, 104, 4, 1286-96 (2008)

33. Y. Samuni, H. Ishii, F. Hyodo, U. Samuni, M. C. Krishna, S. Goldstein, J. B. Mitchell: Reactive oxygen species mediate hepatotoxicity induced by the Hsp90 inhibitor geldanamycin and its analogs. Free Radical Bio Med 48,11, 1559-63 (2010)

34. Z. Mei-Hua, L. Jae-Seon, K. Hee-Jung, J. Dong-I , K. Jong-Il, L. Kong-Joo, S. Jeong-Sun: HSP90 protects apoptotic cleavage of vimentin in geldanamycin-induced apoptosis. $\mathrm{Mol}$ Cell Biochem 281, 111-121 (2006)

35. A. K. McCollum, C. J. TenEyck, B. Stensgard, B. W. Morlan, B. W. Ballman, R. B. Jenkins, D. O. Toft, C. Erlichman: P-glycoprotein-mediated resistance to HSP90directed therapy is eclipsed by the heat shock response. Cancer Res 15, 68, 18, 7419-7427 (2008)

36. N. Pfeiffer: Metastatic Breast Cancer: In Phase I Study, 17AAG Antibiotic + Trastuzumab Shows Promise. Oncology Times 29, 11, 50 (2007)

37. R. K. Ramanathan, D. L. Trump, J. L. Eiseman, C. P. Belani, S. S. Agarwala, E. G. Zuhowski, J. Lan, D. M. Potter, S. P. Ivy, S. Ramalingam, A. Brufsky, M. K. K. Wong, S. Tutchko, M. J. Egorin: Phase I PharmacokineticPharmacodynamic Study of 17- (Allylamino)-17Demethoxygeldanamycin (17AAG, NSC 330507), a Novel
Inhibitor of Heat Shock Protein 90, in Patients with Refractory Advanced Cancers. Clin Cancer Res 11, 3385 (2005)

38. S. Pacey, M. Gore, D. Chao, U. Banerji, J. Larkin, S. Sarker, K. Owen, Y. Asad, F. Raynaud, M. Walton, I. Judson, P. Workman, T. Eisen: A Phase II trial of 17allylamino, 17-demethoxygeldanamycin (17-AAG, tanespimycin) in patients with metastatic melanoma. Invest New Drug 10.1007/s10637-010-9493-4 (2010)

39. N. Gaspar, S. Y. Sharp, S. Pacey, C. Jones, M. Walton, G. Vassal, S. Eccles, A. Pearson, P. Workman: Acquired Resistance to 17-Allylamino-17-Demethoxygeldanamycin (17-AAG, Tanespimycin) in Glioblastoma Cells. Cancer Res 1, 69, 1966 (2009)

40. J. J. Wright: Combination Therapy of Bortezomib with Novel Targeted Agents: An Emerging Treatment Strategy. Clin Cancer Res 10, 1158-1078-0432 (2010)

41. S. Raja, R. J. Clubb, M. Bhattacharyya, M. Dimri, H. Cheng, W. Pan, C. Ortega-Cava, A. Lakku-Reddi, M. Naramura,V. Band, H. Band: A combination of Trastuzumab and 17-AAG induces enhanced ubiquitinylation and lysosomal pathwaydependent ErbB2 degradation and cytotoxicity in ErbB2-overexpressing breast cancer cells. Cancer Biol Ther 7, $10,1630-1640$ (2009)

42. U. N. Vaishampayan, A. M. Burger, E. A. Sausville., L. K. Heilbrun, J. Li, M. N. Horiba, M. J. Egorin, P. Ivy, S. Pacey, P. M. LoRusso: Safety, Efficacy, Pharmacokinetics, and Pharmacodynamics of the Combination of Sorafenib and Tanespimycin. Clin Cancer Res 10.1158/1078-0432.CCR-100503 (2010)

43. S. Modi, S. Sugarman, A. Stopeck, H. Linden, W. Ma, K. Kersey, R. G. Johnson, N. Rosen, A. L. Hannah, C. A. Hudis: Phase II trial of the Hsp90 inhibitor tanespimycin (Tan) + trastuzumab (T) in patients (pts) with HER2-positive metastatic breast cancer (MBC). J Clin Oncol 26, 15S, 1027 (2008)

44. V. Smith, E. A Sausville, R. F. Camalier, H. Fiebig, A. M. Burger: Comparison of 17-dimethylaminoethylamino-17demethoxy-geldanamycin (17DMAG) and 17-allylamino-17demethoxygeldanamycin (17AAG) in vitro: effects on Hsp90 and client proteins in melanoma models. Cancer Chemoth Pharm 5, 2, 126-137 (2005)

45. Guo J., Joseph E., Holleran J., Lagattuta T.F., Covey J.M., Krishnaraj R., Lyubimov A., Gaze E.R., Egorin M.J., Eiseman J.L. 2004. Pharmacokinetics and Pharmacodynamics of 17Dimethylamino-ethylamino-17-demethoxy-geldanamycin (17DMAG, NSC 707545) in Rats. Experimental and Molecular Therapeutics 51: Pharmacokinetics and Pharmacodynamics, Proc Amer Assoc Cancer Res 45 (2004)

46. P. S. Ivy, M. Schoenfeldt: Clinical trials referral resource. Current clinical trials of $17-\mathrm{AG}$ and $17-$ DMAG. Oncology 18, 5, 610, 615, 619-20 (2004) 
47. B. E. Hanson, D. H. Vesole: Retaspimycin hydrochloride (IPI-504): a novel heat shock protein inhibitor as an anticancer agent. Expert Opin Investig Drugs 18, 9, 1375-83 (2009)

48. L. V. Sequist, S. Gettinger, R. Natale, R. Martins, R. Lilenbaum, P. Janne, J. Gray, T. A. Samuel, D. Grayzel, T. J. Lynch; Massachusetts General Hospital Cancer Center, Boston, MA; Yale Comprehensive Cancer Center, New Haven , CT; Cedars-Sinai Medical Center, Los Angeles, CA; Seattle Cancer Care Alliance, Seattle, WA; Mount Sinai Comprehensive Cancer Center, Miami Beach, FL; Dana-Farber Cancer Institute, Boston, MA; H. Lee Moffitt Cancer Center \& Research Institute, Tampa, FL; Medical College of Georgia; Infinity Pharmaceuticals, Inc., Cambridge, MA.: A phase II trial of IPI-504 (retaspimycin hydrochloride), a novel Hsp90 inhibitor, in patients with relapsed and/or refractory stage IIIb or stage IV non-small cell lung cancer (NSCLC) stratified by EGFR mutation status. J Clin Oncol 27, 15 (2009)

49. G. D. Demetri, A. Le Cesne, M. Von Mehren, B. Chmielowski, S. Bauer, W. A. Chow, E. Rodenas, K. McKee, D. S. Grayzel, Y. Kang; Dana-Farber Cancer Institute, Boston, MA; Institut Gustave Roussy, Villejuif, France; Fox Chase Cancer Center, Philadelphia, PA; University of California, Los Angeles, Los Angeles, CA; West German Cancer Center, Duesseldorf, Germany; City of Hope National Medical Center, Duarte, CA; Infinity Pharmaceuticals, Cambridge, MA; Asan Medical Center, Seoul, South Korea: Final results from a phase III study of IPI-504 (retaspimycin hydrochloride) versus placebo in patients (pts) with gastrointestinal stromal tumors (GIST) following failure of kinase inhibitor therapies. 2010 Gastrointestinal Cancers Symposium, Cancers of the Esophagus and Stomach (2010)

50. G. J. Riely, R. Stoller, M. Egorin, D. Solit, J. Dunbar, A. Savage, J. Walker, D. Grayzel, R. Ross, G. J. Weiss; Memorial Sloan-Kettering Cancer Center, New York, NY; University of Pittsburgh Cancer Institute, Pittsburgh, PA; Infinity Pharmaceuticals, Inc., Cambridge, MA; Scottsdale Clinical Research Institute/TGen, Scottsdale: A phase Ib trial of IPI-504 (retaspimycin hydrochloride), a novel Hsp90 inhibitor, in combination with docetaxel. J Clin Oncol 27, 15 (2009)

51. H. Zhang, Y. Yang, L.Zhang, J. Fan, D. Chung, D. Choi, R. Grecko, G. Timony, P. Karjian, M. Boehm, F. Burrows: Dimeric ansamycins-A new class of antitumor Hsp90 modulators with prolonged inhibitory activity. Int $J$ Cancer 120, 4, 918-926 (2007)

52. H. Oppermann, W. Levinson, J. M. Bishop: A cellular protein that associates with the transforming protein of Rous sarcoma virus is also a heat-shock protein. 1981.P Natl Acad Sci USA 78, 2, 1067-1071 (1981)

53. L. Stepanova, X. Leng, S. B. Parker, J. W. Harper: Mammalian $\mathrm{p} 50 \mathrm{Cdc} 37$ is a protein kinase-targeting subunit of Hsp90 that binds and stabilizes Cdk4. Gene Dev 15, 10, 12, 1491-502 (1996)
54. M. J. A. Cote-Veleza, E. Ortegab, A. Ortega: Involvement of pp125FAK and p60SRC in the signaling through Fc $\gamma$ RII-Fc $\gamma$ RIII in murine macrophages. Immunol Lett 78, 3, 189-194 (2001)

55. Y. Uehara, M. Hori, T. Takeuchi, H. Umezawa: Phenotypic Change from Transformed to Normal Induced by Benzoquinonoid Ansamycins Accompanies Inactivation of p6osrc in Rat Kidney Cells Infected with Rous Sarcoma Virus. Mol Cell Biol 2198-2206 (1986)

56. Y. Uehara, Y. Murakami, K. Suzukake-Tsuchiya, Y. Moriya, H. Sano, K. Shibata, S. Omura: Effects of herbimycin derivatives on src oncogene function in relation to antitumor activity. $J$ Antibiot 41, 6, 831-4 (1988)

57. S. D. Hartson, R. L. Matts: Association of Hsp90 with Cellular Src-Family Kinases in a Cell-Free System Correlates with Altered Kinase Structure and Function. Biochemistry 33, 30, 8912-8920 (1994)

58. Y. Xu, S. Lindquist: Heat-Shock Protein hsp90 governs the Activity of pp60v-src Kinase. P Natl Acad Sci of the USA 90, 15, 7074-7078 (1993)

59. G. Odabaei, D. Chatterjee, A. R. Jazirehi, L. Goodglick, K. Yeung, B. Bonavida: Raf-1 kinase inhibitor protein: structure, function, regulation of cell signaling, and pivotal role in apoptosis. Adv Cancer Res 91, 169-200 (2004)

60. T. W. Schulte, M. V. Blagosklonny, L. Romanova, J. F. Mushinski, B. P. Monia, J. F. Johnston, P. Nguyen, J. Trepel, L. M. Neckers: Destabilization of Raf-1 by geldanamycin leads to disruption of the Raf-1-MEKmitogen-activated protein kinase signalling pathway. Mol Cell Biol 16, 10, 5839-45 (1996)

61. T. W. Schulte, M. V. Blagosklonny, C. Ingui, L. M. Neckers: Disruption of the Raf-1-Hsp90 Molecular Complex Results in Destabilization of Raf-1 and Loss of Raf-1-Ras Association. J Biol Chem 270, 41, 24585-24588 (1995)

62. K. Dai, R. Kobayashi, D. Beach: Physical interaction of mammalian CDC37 with CDK4. J Biol Chem 6, 271, 36, 22030-4 (1996)

63. J. Massagu'e: TGF beta signal transduction. Annu Rev Biochem 67, 753-91 (1998)

64. C. H. Yun, S. Y. Yoon, T. T. Nguyen, H. Y. Cho, T. H. Kim, S. T. Kim, B. C. Kim, Y. S. Hong, S. J. Kim, H. J. Lee: Geldanamycin inhibits TGF-beta signaling through induction of Hsp70. Arch Biochem Biophys 1, 495, 1, 8-13 (2010)

65. M. V. Blagosklonny, J. Toretsky, S. Boheni, L. M. Neckers: Mutant conformation of p53 translated in vitro or in vivo requires functional HSP90. P Natl Acad Sci USA 93, 8379-8383 (1996) 
66. M. V. Blagosklonny, J. Toretsky, L. M. Neckers: Geldanamycin selectively destabilizes and conformationally alters mutated p53. Oncogene 7, 11, 5, 933-9 (1995)

67. B. Atrasha, T. S. Coopera, P. Sheldrakea, P. Workmana, E. McDonald: Development of synthetic routes to macrocyclic compounds based on the HSP90 inhibitor radicicol. Tetrahedron Lett 47, 13, 2237-2240 (2006)

68. P. Workman, I. Collins: Probing the Probes: Fitness Factors For Small Molecule Tools. J Chem Biol 25, 17, 6, 561-577 (2010)

69. S. Soga, S. V. Sharma,Y. Shiotsu, M. Shimizu, H. Tahara, K. Yamaguchi, Y. Ikuina, C. Murakata, T. Tamaoki, J. Kurebayashi: Stereospecific antitumor activity of radicicol oxime derivatives. Cancer Chemoth Pharm 48, 6, 435-445 (2001)

70. M. Marcu, A. Chadli, I. Bouhouche, M. Catelli, L. M. Neckers: The Heat Shock Protein 90 Antagonist Novobiocin Interacts with a Previously Unrecognized ATPbinding Domain in the Carboxyl Terminus of the Chaperone. J Biol Chem 275, 37181-37186 (2000)

71. R. J. Lewis, O. M. Singh, C. V. Smith, T. Skarzynski, A. Maxwell, A. J. Wonacott, D. B. Wigley: The nature of inhibition of DNA gyrase by the coumarins and the cyclothialidines revealed by X-ray crystallography. EMBO $J 15,15,6,1412-20$ (1996)

72. M. Marcu, T. W. Schulte, L. M. Neckers: Novobiocin and Related Coumarins and Depletion of Heat Shock Protein 90-Dependent Signaling Proteins. $J$ Natl Cancer Inst 92, 3, 242-248 (2000)

73. B. G. Yun, W. Huang, N. Leach, S. D. Hartson, R. L. Matts: Novobiocin Induces a Distinct Conformation of Hsp90 and Alters Hsp90-Cochaperone-Client Interactions. Biochemistry 43, 25, 8217-8229 (2004)

74. S. B. Matthews, G. A. Vielhauer, C. A. Manthe, V. K. Chaguturu, K. Szabla, R. L. Matts, A. C. Donnelly, B. S. Blagg, J. M. Holzbeierlein: Characterization of a novel novobiocin analogue as a putative C-terminal inhibitor of heat shock protein 90 in prostate cancer cells. Prostate 1, $70,1,27-36(2010)$

75. J. K. McCleese, M. D. Bear, S. L. Fossey, R. M. Mihalek, K. P. Foley, W. Ying, J. Barsoum, C. A. London: The novel HSP90 inhibitor STA-1474 exhibits biologic activity against osteosarcoma cell lines. Int J Cancer 125, 2792-2801 (2009)

76. Y. Fukuyo, C. R. Hunt, N. Horikoshi: Geldanamycin and its anti-cancer activities. Cancer Lett 290, 24-35 (2010)

Abbreviations: 17AAG: 17- (Allylamino)-17demethoxygeldanamycin, Cdc: cyclin dependent kinases, CHIP: carboxy-terminus of Hsp70 interacting protein, 17-DMAG: 17-dimethylaminoethylamino-17demethoxygeldanamycin, GA: geldanamycin, Hsps: heat shock proteins, IPI-504: 18, 21-Didehydro-17demethoxy-18,21-dideoxo-18,21-dihydroxy-17- (2propenylamino)geldanamycin, TGF-beta: transforming growth factor beta

Key Words: Anticancer drugs, Geldanamycin, 17AAG, 17-DMAG, IPI-504, STA-9090, STA-1474, Radicicol, Novobiocin, Hsp90, Hsp90 inhibitors, Hsp90 client proteins, Review

Send correspondence to: Magdalena Gorska, Departament of Medical Chemistry, Medical University of Gdansk, Debinki 1, 80-211, Gdansk, Poland, Tel: 485834914 50, Fax: 485834914 56, E-mail: m.gorska@gumed.edu.pl 